\title{
Engaging Students in the Advancement of a Music Economy: A Case Study
}

\author{
Storm Gloor \\ University of Colorado Denver \\ This paper was presented at the 2019 International Summit of the \\ Music \& Entertainment Industry Educators Association \\ March 21-23, 2019
}

$\underline{\text { https://doi.org/10.25101/19.33 }}$

\section{Abstract}

Arvada, Colorado could hardly be identified as having a significant reputation for its music scene. Essentially a suburb of Denver, residents typically find their entertainment in that larger city or in Boulder or Morrison (Red Rocks), among other places. On the other hand, the city of roughly 100,000 draws vast amounts of outsiders to its amazing arts center and the area known as "Olde Town" could experience a massive rebirth if a planned mass transportation strategy comes to fruition. The potential to grow the music and arts economy in Arvada, Colorado was a key incentive for the city to enlist in the Hometown Colorado Initiative (HCI), a program that engages universities in communities with the mission of deploying students in service-learning-type research aimed at addressing "real world" problems and challenges as they interact with public servants and citizens. In a sense, the world just beyond campus becomes the laboratory where students put their learned knowledge and skills to work for the better good all the while under the wing of academia.

Four students undertook just such an endeavor in Arvada as they researched the music economy and developed sixteen potential projects to further develop it, prior to carrying out four of those initiatives. The planning, implementation, and execution of the "Arvada Music Project" greatly informed how this academic experience could be utilized elsewhere within higher education partnerships with their communities. We will discuss here the valuable learnings and best/worst practices that can be carried forth from this project.

Keywords: Hometown Colorado Initiative, Arvada, Colorado, service learning, Arvada Music Project, music economy, music cities, University of Colorado Denver

\section{Introduction}

Involving students in hands-on projects to enhance the learning experience is certainly nothing new as a curricular strategy. Whether through a lab project or a field study, engaging students in such active learning experiences has proven to be educationally beneficial. ${ }^{1}$ The aim of one such experience at the University of Colorado Denver was to expand a relatively new area of study by introducing a service learning type of student project intended to engage them in improving their local community, particularly its music economy.

This particular project, completed in partnership with the Hometown Colorado Initiative, involved students in the Music Cities course working within the city of Arvada, Colorado for one year to conduct research and design plans to enhance the community's music economy. While it may or may not have been a unique, or even successful, endeavor, much was gained from the experience in terms of learning how to further enhance and improve this type of instruction and curriculum. For example, what should be kept in mind in pursuing other similar projects, and how can they more effectively achieve their intended outcomes? Those were among the questions answered as a result of participation in this academic endeavor.

\section{The Music Cities Course and the $\mathrm{HCl}$}

The College of Arts \& Media (CAM) at the University of Colorado Denver first offered a Music Cities course in the fall of 2015. Subsequent to that semester, it has been made available to students each spring semester. In the summer of 2017, various CU Denver instructors were contacted in regard to upcoming projects being planned by the Hometown Colorado Initiative (HCI), in partnership with the city of Arvada, Colorado. The HCI's mission is to "connect communities in Colorado with the wide-ranging knowledge and discipline of the University of Colorado faculty and students to address local issues that advance community livability and quality of life." ${ }^{2}$ The program is very similar to the University of Oregon's Sustainable City Year Program, 
which pairs students with Oregon cities, counties, special districts, tribes, or partnerships for an entire academic year, during which students "work on partner-identified projects through existing courses to provide ideas for real solutions to community challenges and sustainable development." ${ }^{\text {In }}$ essence, students are immersed in research projects in the community as a type of service learning exercise aimed at enhancing their abilities while "giving back" as they apply what they've learned in the classroom to their surrounding community.

While HCI had already partnered with Arvada on projects to, among other objectives, address attainable housing, parking and travel demand, and water conservation, the city was also interested in gaining analysis of its music and arts economy. Given the alignment between that objective and the curriculum in the Music Cities course, it made sense that students from that class would be best equipped to deliver what Arvada and the HCI were seeking in their call out. Once that became apparent, introductory meetings between CU Denver faculty and Arvada city officials were held to cement expectations and establish communications.

\section{Arvada, Colorado}

The city of Arvada is home to approximately 119,000 Coloradoans. ${ }^{4}$ It's the seventh most populated municipality in the state, and the city's Olde Town historic district is located only seven miles from the state capitol in Denver. ${ }^{5}$ The median age in Arvada is 41, as compared to the Colorado average of $36 .{ }^{6} 80.4 \%$ of its citizens are White/Caucasian, $14.5 \%$ are Hispanic, and $2.0 \%$ are Asian. ${ }^{7}$

It's not as if the city had a weak music or arts scene. For many years, The Arvada Center has been a significant cornerstone to the community's arts and humanities endeavors. Among other activities, the Center hosts theater, music, and visual arts events, maintains a prestigious gallery, and offers arts-related classes. ${ }^{8}$ Among the music offerings, its Summer Concert Series has included many national touring acts, including Pat Benatar, Los Lonely Boys, Air Supply, and others. ${ }^{9}$ Established in 1976 as a municipally owned and operated facility, on July 6, 2015, the Arvada City Council voted unanimously to change their relationship and establish the Arvada Center for the Arts and Humanities as an independent nonprofit responsible for its own operation and fundraising. ${ }^{10}$ Presumably to shift focus to the arts community outside of the Center, the Council subsequently, in 2016, established a new Arvada Arts and Culture Commission. ${ }^{11}$ The goal of that Commission was to "create a strategic plan for public art in the community as well as to foster closer relationships with all artists living and working in Arvada." 12

Outside of the Arvada Center, the music scene had in recent years suffered some setbacks. As one example, for more than a decade, the D Note, located in Olde Town Arvada, had been a prominent music venue, frequented by many visitors from inside and outside of the city. ${ }^{13}$ It's closing on January 3, 2014, had apparently left a void in terms of spaces for local artists to perform. ${ }^{14}$

The Arvada Center transition, the closing of the D Note, and other changes in the city were brought up in initial meetings as concerns that had affected the music economy in the recent past. On the other hand, faculty were also informed of changes ahead. The completion of a planned "G Line" commuter train that would connect Denver to Arvada and other cities was still at the time under construction, though completion was going to be considerably delayed. ${ }^{15}$ A route stop in Olde Town had already been constructed.

These transitions and others were convincing enough that it was an opportune time to consider the future of the music economy, and that of the arts in general, for the City of Arvada. And with the HCI's assistance available, participation in such a study by the Music Cities students made logical sense as it got underway.

\section{Phase One: The Research Stage}

The project began in earnest in the fall semester of 2017. An initial challenge was the fact that the Music Cities course was not offered that semester. As an alternative, four students who'd completed the class the prior spring semester were selected to conduct the research as an independent study course. The objective of this first phase of the project was to analyze the city's music economy and develop recommended projects that would be intended to strengthen it. The team would ultimately need to deliver sixteen recommendations from which, based on the city's selection, the priority projects would be mutually determined. With that in mind, the students initially focused on research and discovery of the priority issues and concerns relating to the city's music and arts economy.

After briefing meetings with Ryan Stachelski, Director of the Arvada Economic Development Association and the designated point-person for the partnership, the students conducted qualitative research throughout the semester. Their work included interviews with music-related business owners, meetings with the aforementioned Arvada Arts and Culture Commission (AAC), and conversations with other interested parties. The team met with directors of various key city attractions and city offices, including the Department of Tourism and the Apex Center, which, at 168,500 square feet is "one of the nation's largest public recreation centers" and one of the higher trafficked areas in Arvada. ${ }^{16}$ Students also attended city council meetings and visited with citizens during various public events, including the city's annual A Chocolate Affair event. ${ }^{17}$ A survey instrument was also developed to garner quantitative data for the 
study.

Just prior to the partnering of HCI and Arvada, the Arts and Culture Commission had enlisted a consulting company to assist in building the master plan for the arts in Arvada. On the surface it may have seemed that the work of those consultants and the CU Denver students might be redundant. However, the two groups and faculty quickly met to discuss their objectives and found that their work would actually be complementary. The consultants subsequently included the students in their presentations, field trips, and brainstorming sessions. Students gained a great deal of helpful insights and data from observing these activities.

Once all the data were accumulated and reviewed, the students did indeed identify the sixteen potential initiatives that could enhance Arvada's music scene and economy. They presented all of those proposals during an extended working session at the end of the semester with Mr. Stachelski, four members of the Arts and Culture Commission, and the consulting team. From those discussions, four projects were selected based on their perceived value, consistency with the city's overall community vision, and whether they could, as a best estimate, feasibly be achieved within the following semester. The selected proposals were as follows:

\section{The "Tour De Park" Festival}

Arvada prides itself on the number of public parks within its community. All residents are within a half-mile of an Arvada Park. ${ }^{18}$ The intent with this project was to create a one-day event in which live music would be featured in many of the parks simultaneously. Attendees would be encouraged to travel between parks (some within walking or biking distance) by contests and various strategies in the programming. Arts and crafts exhibits, installations, and vendor tables would be available in each of the activated parks as well.

\section{Arvada Skate Park Day}

In their research, students discovered that Arvada was home to the third largest skate park in the country, a fact that they also found to be less widely known than expected. ${ }^{19}$ The team also observed that there were few venues for younger musicians to perform in the city. Based on these findings the students developed a proposed daytime event that would bring attention to the skate park and feature music appealing to a younger demographic. This event would also include exhibits of other art, while still maintaining a focus on a younger audience.

\section{The Arvada Artist Database}

Another finding in the student research was that there wasn't enough useful data on just how many musicians resided in the community, much less any way to efficiently communicate with them. This need existed for other arts practitioners as well. In order to have solid data for any future requests or policy proposals put forward to city councils or grant providers, a gathering of such information would be imperative. Having the ability to communicate broadly to artists of all disciplines would also improve notifications of events and build networks. These were some of the motivations behind selecting the building of a platform that would allow artists to add themselves to a database that could be utilized by the city and any public entities. The students proposed building such a platform for the city's use.

\section{The Arvada Music and Arts Newsletter}

The students also felt that an "old school" (hardcopy) communication piece needed to be developed not only to enhance the arts community in Arvada but to also serve as a marketing piece to citizens as well as visitors. The newsletter was envisioned to be a sort of guide for anyone to find at a hotel, visitors center, restaurant, etc., to readily find out about the arts and cultural events taking place, profiles of local musicians and music venues, or any other content that might better brand the city's music and arts scene. This project would involve working with the Arvada Visitors Center.

\section{Phase Two: Project Development Stage}

Phase two of the project began when the spring 2018 Music Cities course was underway. Twenty-three students were divided into four teams, each to work on one of the four initiatives. The first step, of course, was to have them review the research of the prior semester and meet with city officials for briefings and updates.

During the semester, two of the teams met with more citizens and community leaders as they developed marketing plans for the Tour de Park and Skate Park events. A meeting with Brenda Berg, the Special Events Coordinator for the city, for example, proved fruitful in understanding her expectations and priorities. Additional meetings with the Arvada Festivals Commission also provided useful feedback to the students. About halfway through the semester, both teams visited the Arvada City Hall and conducted in-person presentations of the general outlines of their plans and gathered further feedback from an even larger Festivals Commission group. Their feedback at that time also proved fruitful.

The team working on the database project engaged directly with two members of the Arts and Culture Commission, Marty Myers and Pete Simon, who also proved to be extremely helpful to the development of the platform. This project had perhaps the most difficult issues to resolve. For example, to whom would the gathered data belong? Who could ensure privacy, prevent misuse, etc.? A website would need to be created to perpetually be available to artists new to the community or missed in the initial call-out to add their information. But would that page reside on the City 
of Arvada website, the Arts and Culture Commission's, or both, and who would maintain it? A meeting with IT personnel was of course necessary to resolve those issues and others.

The newsletter project team perhaps had the least difficult task. Because there was no such preexisting marketing piece, they were given relatively free rein to develop ideas after gathering initial feedback from Jean Gordon of the Arvada Visitors Center, with additional suggestions along the way. While the boundaries for the newsletter format, design, and content might have been less limited, the biggest challenge with this project was the implementation and distribution of the document.

The teams met regularly, inside and outside the classroom, sometimes during the class sessions and sometimes outside of them. This group work, though, did not replace any portion of the usual Music Cities curriculum, which continued in the same manner and at the same pace as previous offerings of the course. Teams experienced the usual challenges that typically come with group work: some students consistently missed meetings, contributed less than their share, etc. And as one might expect, leaders organically emerged within the teams the more they worked together.

\section{Project Conclusion and Takeaways}

At the end of the semester links to the marketing plans for the two events and a mock up for the newsletter were included in the final report delivered to city officials. In addition, a meeting was held with leaders of the AAC, during which they were presented the passwords to the database website and given a demonstration of how it operated. The reports were generated through coordination with the HCI and designed by one of the students from phase one of the project.

As with any first-time experience, there was plenty to learn from activating students in the community as part of the Music Cities course, particularly from an educator's perspective. Since a post-project survey or evaluation form was not delivered to the students or city officials, the observations are for the most part anecdotal.

At the conclusion of their work, students essentially left the city of Arvada with a to-do list. There were probably means to ensure a better hand-off than that final presentation and delivery. Earlier involvement by the individuals who would take on the duties, a more detailed timing plan as part of the documentation, or a follow-up schedule involving subsequent Music Cities courses are among the possible solutions.

Though it would apply with any partnership involving an educational institution, the academic calendar can affect projects like these. For example, momentum was lost during holiday breaks and exam periods. The two festivals/ events would need to be held in the summer time. But since the marketing plans were being built in the spring semester, it meant that the they would have to wait until the following summer (of 2019), when it would be difficult to re-involve the students who prepared the plans and also possibly lose momentum during the long wait.

Again, a first-time experience intrinsically means that one could find many opportunities in hindsight. But the benefits of the student experience can't be overlooked. Students had the opportunity to engage with public officials to address real-world and real-time problems. They organized as teams to achieve outcomes. Their professionalism and presentation skills were put to the test more effectively than a simulated environment would have allowed. It was in many ways a unique experience that forced the students to creatively problem-solve and to enhance their critical thinking skills. For those reasons alone, the work done by Music Cities students for the City of Arvada was worth the time and effort.

\section{Endnotes}

1. Jeffrey Selingo, "Hands-on learning is a necessary part of college, but here's what it doesn't teach students,"

The Washington Post, June 22, 2018, https://www. washingtonpost.com/news/grade-point/wp/2018/06/22/ hands-on-learning-is-a-necessary-part-of-collegebut-heres-what-it-doesnt-teach-students/?noredirect $=$ on\&utm term $=.1$ fe8adc68c91.

2. https://www1.ucdenver.edu/centers/city-center/hometown-colorado, accessed June 26, 2019.

3. https://sci.uoregon.edu/sustainable-city-year-program-0, accessed June 26, 2019.

4. https://arvada.org/about/our-community/profile, accessed June 25, 2019.

5. https://en.wikipedia.org/wiki/Arvada,_Colorado, accessed June 25, 2019.

6. https://www.areavibes.com/arvada-co/demographics/, accessed June 22, 2019.

7. https://www.colorado-demographics.com/arvada-demographics, accessed June 23, 2019.

8. https://arvadacenter.org/about-the-center, accessed June 25, 2019.

9. BMW News Desk, "The Arvada Center announces 2018 Summer at the Center Concerts," (Denver: Broadway World, April 18, 2018).

10. Eden Lane, "How The Arvada Center Celebrates 40 Years of Creativity By Recreating Itself," HuffPost, August 2, 2016, https://www.huffpost.com/entry/howthe-arvada-center-cel b 11289504.

11. https://arvada.org/explore/culture-and-community/cul- 
ture-and-community, accessed June 26, 2019.

12. Ibid.

13. Jon Solomon, "D Note's January 3 Closing Will Leave a Hole in Olde Town Arvada," Westword, December 29, 2014, https://www.westword.com/music/d-notesjanuary-3-closing-will-leave-a-hole-in-olde-town-arvada-6044402.

14. Ibid.

15. Jay Bouchard, "RTD Finally Announces an Opening Date for the G Line," 5280 Magazine, April 1, 2018, https://www.5280.com/2019/04/rtd-finally-announcesan-opening-date-for-the-g-line/.

16. Margaret Ahrweiler, "The Apex of it All," Recreation Management, May/June 2002. http://recmanagement. com/feature/200205FP01.

17. Kathryn Scott, "Photos: A peek at Arvada's annual chocolate-tasting event, A Chocolate Affair," Denver Post, February 7, 2018, https://www.denverpost. com/2018/02/07/photos-a-chocolate-affair-arvada/.

18. https://arvada.org/about/our-community/profile, accessed June 18, 2019.

19. https://arvada.org/explore/sports-recreation/skateboard-parks, accessed June 19, 2019.

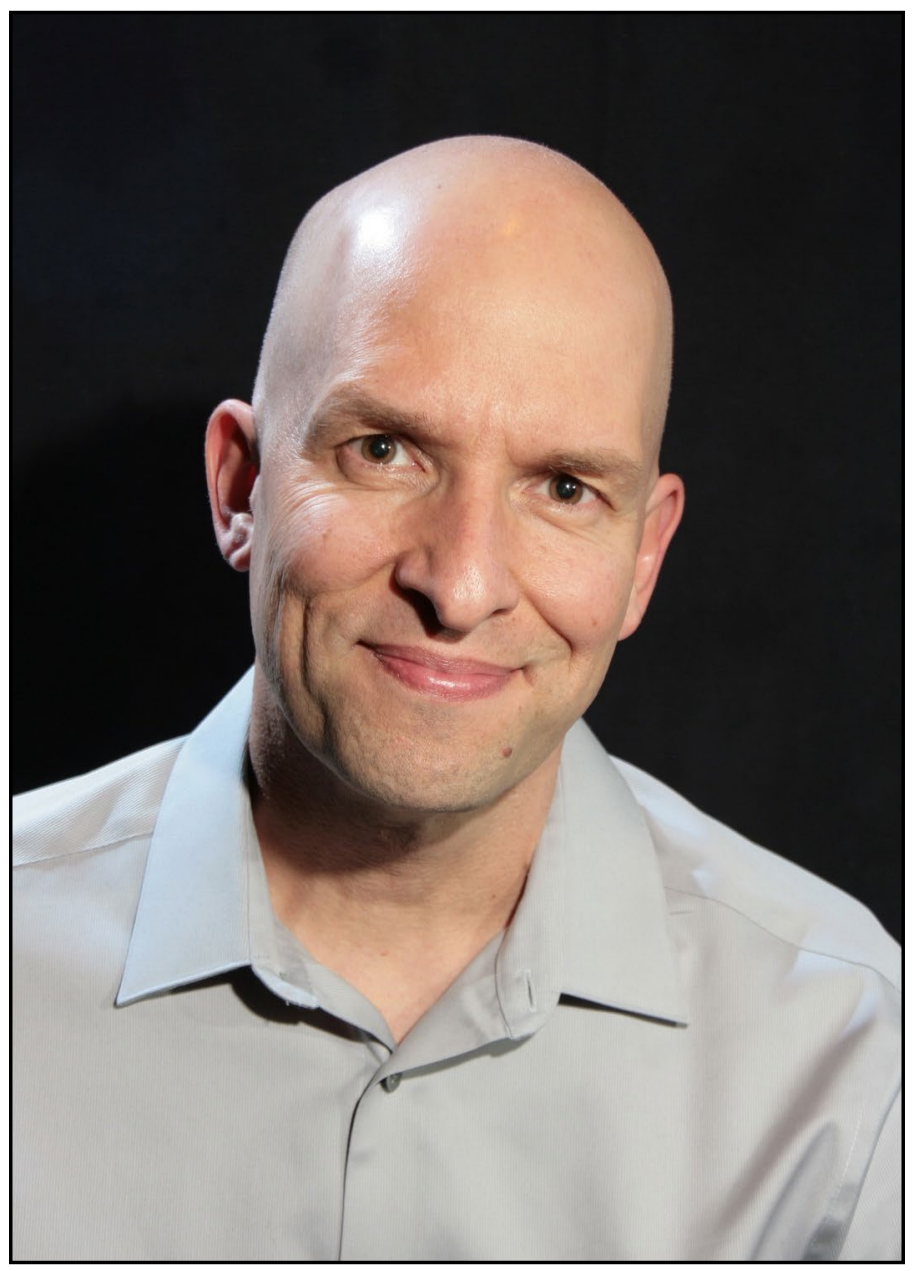

Storm Gloor is an associate professor in the Music and Entertainment Industry Studies Department of the College of Arts and Media at the University of Colorado Denver. He is the recipient of the university's 2018 Excellence In Teaching Award. In 2014, Professor Gloor developed the first Music Cities higher education course in the world. Along with that course, Professor Gloor teaches Music Marketing and oversees the internships for the College of Arts and Media. As part of the First Year Experience program at CU Denver, he teaches a course on the Beatles. Professor Gloor is also a Faculty Fellow in the Center for Faculty Development, is a past president of the Music and Entertainment Industry Educators Association, and serves as a city councilman for Glendale, Colorado. He has presented at numerous events and programs, including SXSW.edu, South By Southwest Music, the Music Cities Convention, the Future of Music Summit, the Underground Music Showcase, the Denver Music Summit, and an EdMedia world conference. 


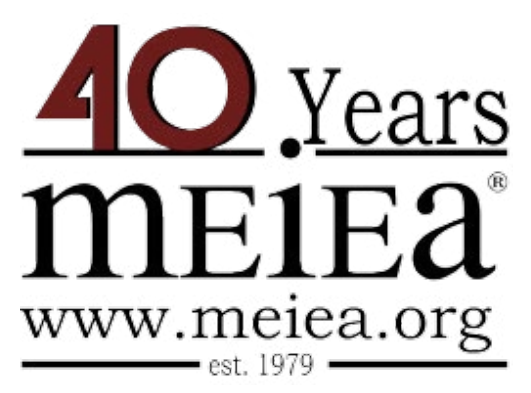

\section{PROCEEDINGS OF THE \\ 2019 INTERNATIONAL SUMMIT \\ OF THE \\ MUSIC \& ENTERTAINMENT \\ INDUSTRY EDUCATORS \\ ASSOCIATION}

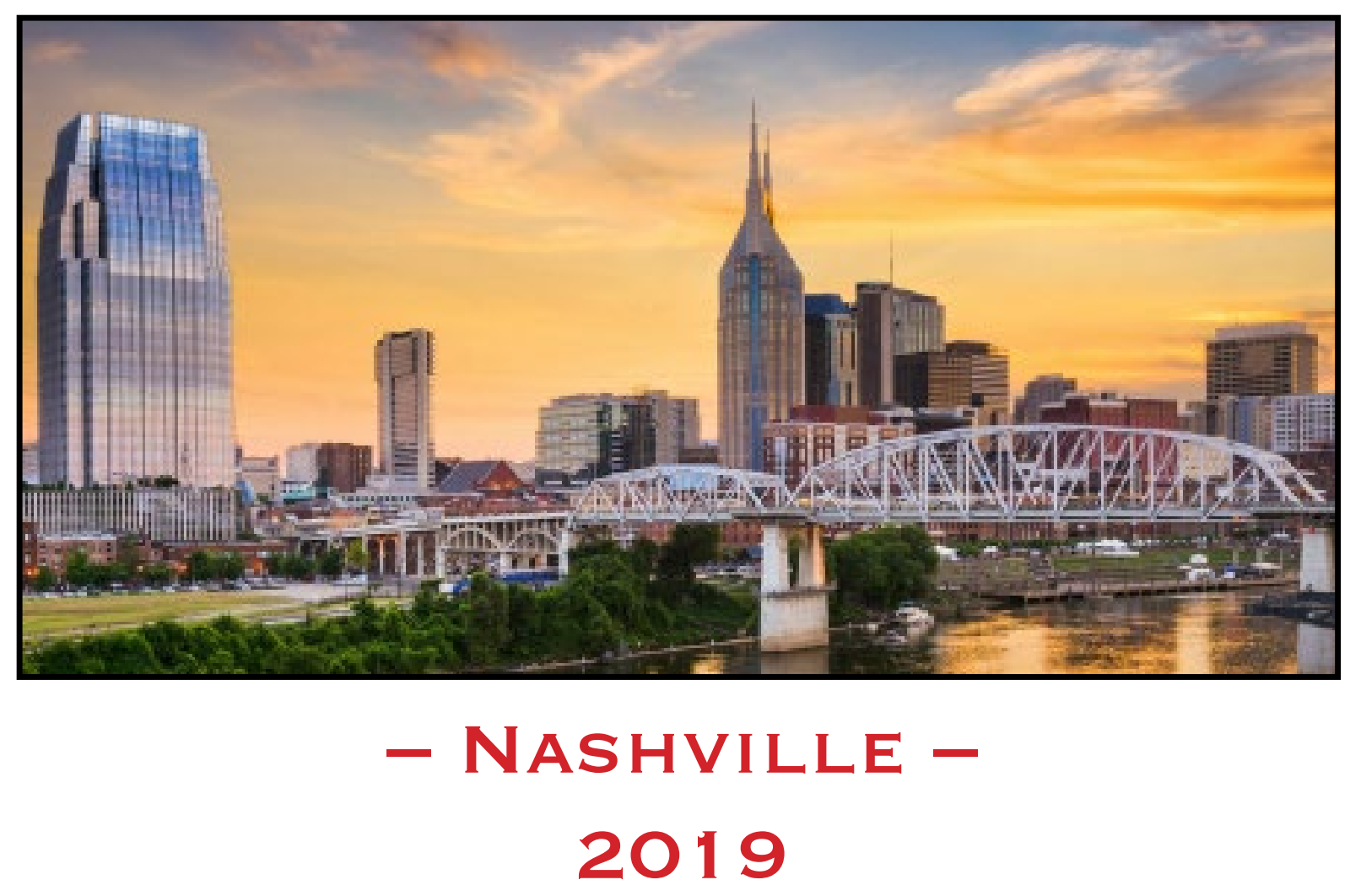

March 21 - 23, $2019 \cdot$ Belmont University - Nashville 